\title{
Fos-Related Antigen 2: Potential Mediator of the Transcriptional Activation in Rat Adrenal Medulla Evoked by Repeated Immobilization Stress
}

\author{
Bistra B. Nankova, ${ }^{1}$ Mark Rivkin, ${ }^{1}$ Max Kelz, ${ }^{2}$ Eric J. Nestler, ${ }^{2}$ and Esther L. Sabban ${ }^{1}$ \\ ${ }^{1}$ Department of Biochemistry and Molecular Biology, New York Medical College, Valhalla, New York 10595, and \\ ${ }^{2}$ Departments of Psychiatry and Neurobiology, Yale University School of Medicine and Connecticut Mental Health Center, \\ New Haven, Connecticut 06508
}

\begin{abstract}
The precise mechanisms by which beneficial responses to acute stress are transformed into long-term pathological effects of chronic stress are largely unknown. Western blot analyses revealed that members of the AP1 transcription factor family are differentially regulated by single and repeated stress in the rat adrenal medulla, suggesting distinct roles in establishing stressinduced patterns of gene expression in this tissue. The induction of c-fos was transient, whereas marked elevation of long-lasting Fos-related antigens, including Fra2, was observed after repeated immobilization. We investigated DNA protein interactions at the AP1-like promoter elements of two stress-responsive genes, tyrosine hydroxylase and dopamine $\beta$-hydroxylase. Increased DNA-binding activity was displayed in adrenomedullary extract from repeatedly stressed rats, which was predominantly
\end{abstract}

Immunolocalization of immediate-early gene (IEG) products and especially c-fos is widely used as a functional marker to identify activated neurons and extended circuitries that are responsive to a variety of extracellular challenges (Morgan and Curran, 1995; Chaudhuri, 1997; Kovacs, 1998). Different types of acute stress increase the expression of c-fos and other IEGs in specific brain regions and in peripheral tissues (Palkovits et al., 1995; Senba and Ueyama, 1997; Del et al., 1998). The induction of c-fos expression is typically transient. In contrast, chronic glucocorticoid administration as well as repeated stress attenuate the subsequent acute immobilization stress-induced expression of c-fos, Fos B, Jun B, and Egr1 (Umemoto et al., 1997). These results suggest that other members of the AP1 family may mediate the effects of chronic stimuli. Examples of sustained elevations in the expression of other members of c-fos family in the brain provoked by chronic stimuli have been reported. These Fos-like proteins, termed chronic Fosrelated antigens (Fras), are induced in a region-specific manner in response to several chronic perturbations, including: electroconvulsive seizures, administration of cocaine, morphine, and nicotine, and psychotropic drug treatments and lesions (Hope et al., 1994b; Nye et al., 1995; Pennypacker and Hong, 1995; Bing et al., 1996; Doucet et al., 1996; Moratalla et al., 1996; Nye and Nestler, 1996; Pich et al., 1997; Atkins et al., 1999). Once induced, the chronic Fras, shown to be the truncated splice variant of the FosB geneDelta FosB isoforms, accumulate for relatively long periods because of their high stability. They are attractive candidates for mediating some of the longer-lasting transcriptional changes in-

\footnotetext{
Received Feb. 22, 2000; revised April 27, 2000; accepted May 15, 2000.

This work was supported by National Institute of Health Grants NS28869 to E.S and MH53199 to E.N. We thank Dr. Lidia Serova for helpful discussion and Dr. Alison Beckmann for the chronic ECS samples.

Correspondence should be addressed to Dr. Esther L. Sabban, Department of Biochemistry and Molecular Biology, New York Medical College, Valhalla, NY 10595. E-mail: Sabban@NYMC.edu.

Copyright (C) 2000 Society for Neuroscience $0270-6474 / 00 / 205647-07 \$ 15.00 / 0$
}

composed of c-Jun- and Fra2-containing dimers. The induction of Fra2 and increased AP1-like binding activity was reflected in sustained transcriptional activation of tyrosine hydroxylase and dopamine $\beta$-hydroxylase genes after repeated episodes of stress. The functional link between Fra2 and regulation of tyrosine hydroxylase and dopamine $\beta$-hydroxylase transcription was confirmed in PC12 cells coexpressing this factor and the corresponding promoter-reporter gene constructs. These studies emphasize the potential importance of stress-evoked increases in the expression of the Fra2 gene for in vivo adaptations of the adrenal catecholamine producing system.

Key words: AP1-like factors; Fra2; repeated stress; adrenals; transcription; tyrosine hydroxylase; dopamine $\beta$-hydroxylase volved in the regulation of the brain function (Chen et al., 1997; Nestler et al., 1999).

Many stress-responsive genes, including those encoding catecholamine biosynthetic enzymes tyrosine hydroxylase $(\mathrm{TH})$ and dopamine $\beta$-hydroxylase (DBH), contain AP1-like binding sites in their promoters, and AP1 factors could be important in establishing stress-induced patterns of gene expression in different tissues. We have shown previously that the transcriptional activation of $\mathrm{TH}$ and DBH in adrenal medulla of animals exposed to immobilization stress is correlated with increased binding of AP1 factors to oligonucleotides comprising their AP1-like promoter elements (Nankova et al., 1993, 1994, 1999). Nevertheless, our studies with $c$-fos knock-out mice revealed that c-fos is not essential for the induction of adrenal TH and DBH genes by repeated stress (Serova et al., 1998).

How the expression of different members of the extended Fos family of proteins is regulated by acute and chronic challenges in the adrenal medulla is important in understanding their role in mediating the stress response. The present study was undertaken to examine the expression patterns of c-fos- and Fos-related proteins in animals exposed to different stress paradigms. We found differential induction of c-fos and other Fos-related antigens, particularly Fra2, by single and repeated immobilization stress. The functional differences between the AP1 complexes induced by single and repeated stress can be attributed to differences in the composition of AP1 DNA-binding complexes formed in response to each challenge.

\section{MATERIALS AND METHODS}

Immobilizations. Male, murine pathogen-free, Sprague Dawley rats (280$320 \mathrm{gm}$ ) were obtained from Taconic (Germantown, NY). Immobilization stress was performed as previously described (McMahon et al., 1992; Nankova et al., 1996). For repeated stress, the animals were immobilized for $2 \mathrm{hr}$ daily on consecutive days. Control groups were either not exposed to stress (absolute controls) or handled briefly on each day for the same number of days as the animals exposed to repeated immobilization stress (handled controls). The animals were killed by decapitation. The adrenal 
medullae from 10 to 12 animals per experimental group were dissected and frozen immediately on liquid nitrogen.

Electroconvulsive seizure. Electroconvulsive shock (ECS) treatments were performed as described earlier (Hope et al., 1994a). Briefly, male Sprague Dawley rats $(150-250 \mathrm{gm})$ were connected to earclip electrodes. For chronic studies, animals received a single ECS (45 mA; $0.3 \mathrm{sec})$ daily for $10 \mathrm{~d}$, and they were then killed $18 \mathrm{hr}$ after the last treatment. The acute and control animals were also connected to the electrodes, but no current was applied. Such previous sham treatments were used to reduce the effects of handling stress (Campeau et al., 1991; Sharp et al., 1991). On day 11, acute animals were given a single ECS and were killed $2 \mathrm{hr}$ later. Dorsal parietal and prefrontal cortex were obtained and immediately frozen on liquid nitrogen.

Nuclear extracts. Nuclear protein extracts were prepared (Dignam et al., 1983) from frozen punches of adrenal medullae of control rats and rats exposed to repeated immobilization stress as described earlier (Nankova et al., 1993; Sabban et al., 1995).

Electrophoretic mobility shift assays. DNA-protein-binding reactions were performed at room temperature for $30 \mathrm{~min}$ in binding buffer $(12 \%$ glycerol, $12 \mathrm{~mm}$ HEPES, $8 \mathrm{~mm}$ Tris-HCl, $1 \mathrm{~mm}$ EDTA, $1 \mathrm{~mm}$ DTT, and 60 $\mathrm{mM} \mathrm{KCl})$. The standard reaction included: $1 \mu \mathrm{g}$ of BSA, $1 \mu \mathrm{g}$ of poly(dI$\mathrm{dC}), 0.5 \mathrm{ng}$ of ${ }^{32} \mathrm{P}$-end labeled double-stranded oligonucleotide $(\sim 30,000$ $\mathrm{cpm}$ of radioactive probe) and nuclear extract (3-5 $\mu \mathrm{g}$ of protein) in a final volume of $15 \mu \mathrm{l}$. Competition was performed by adding a 100 -fold molar excess of nonradioactive oligonucleotides to the reaction before the nuclear extracts. For antibody supershift experiments, 1-2 $\mu \mathrm{g}$ of antiserum were preincubated for $30 \mathrm{~min}$ at room temperature with the nuclear extract before adding the binding oligonucleotide directly or after heating for $1 \mathrm{hr}$ at $90^{\circ} \mathrm{C}$. The DNA-protein complexes were resolved on $6 \%$ polyacrylamide gels in $0.25 \times$ Tris-borate buffer. Subsequently, the gels were fixed, vacuum-dried, and autoradiographed using intensifying screens and Kodak XAR-5 film. Each binding assay was repeated at least three times, with extracts from independent experiments.

The following antibodies were used in this study: c-fos (epitope corresponding to N-terminal amino acids 3-16), Fra1 (epitope corresponding to N-terminal amino acids 3-22 of human Fra1, specific for Fra1), Fra2 (rabbit polyclonal antibody raised against a peptide corresponding to amino acids 3-22 mapping at the amino terminus of Fra2 of human origin), and FosB (epitope corresponding to amino acids 102-117, specific for FosB and delta FosB). All were purchased from Santa Cruz Biotechnology (Santa Cruz, CA). The cAMP response element modulator (CREM) family-specific antibody (recognizes all known CREM isoforms) was from Upstate Biotechnology (Lake Placid, NY), and N-terminal c-fos antibody (against amino acids 1-111, broadly reactive with c-fos, FosB, Fra1, and Fra2) was from Oncogene Science. Jun-family antibody was a gift from Dr. R. Bravo (Bristol-Myers Squibb Pharmaceutical Research Institute, Princeton, NJ). The antibody recognizing all family of the Fos-related antigens was a gift from Dr. M. Iadarola (National Institutes of Health, Bethesda, MD). The oligonucleotides were synthesized by BioServe Biotechnologies and are shown on the corresponding figures.

Western blot analysis. Total protein extracts from adrenal medullae of individual animals (four to eight rats from each experimental group) were prepared as follows: frozen tissues were homogenized on ice in $20 \mathrm{~mm}$ HEPES, pH 7.5, $350 \mathrm{~mm} \mathrm{NaCl}, 25 \%$ glycerol, $0.25 \%$ NP-40, $1 \mathrm{~mm}$ $\mathrm{Na}_{2} \mathrm{VO}_{3}, 0.25 \mathrm{~mm} \mathrm{PMSF}, 5 \mathrm{mM} \mathrm{MgCl}_{2}$, and $1 \mu \mathrm{g} / \mathrm{ml}$ each of aprotenin, pepstatin, and leupeptin, $1 \mathrm{~mm}$ EGTA, and $1 \mathrm{~mm}$ DTT. The homogenates were subsequently clarified by centrifugation. Protein concentration was determined using the Bradford assay. For immunoblots, equal amounts of proteins were separated on $10 \%$ SDS-PAGE and electroblotted onto a nitrocellulose membrane (Bio-Rad, Hercules, CA). After blocking, the membranes were incubated with appropriate amounts of primary antibody at $4^{\circ} \mathrm{C}$ overnight. The secondary antibody (goat anti-mouse IgG; Pierce, Rockford, IL) was diluted 1:30,000. An enhanced chemiluminescent substrate (Pierce) using either alkaline phosphatase or horseradish peroxidase label was used for the visualization of the immunoblots.

Nuclear run-on assay. The rates of TH and DBH gene transcription in adrenal medulla of control rats and in rats exposed to immobilization stress were measured by using the method of McKnight and Palmiter (1979), as described in detail by Fossom et al. (1992). For the isolation of nuclei, freshly dissected adrenal medullae from four animals per group were pooled and homogenized at $4^{\circ} \mathrm{C}$ in buffer containing $140 \mathrm{~mm} \mathrm{NaCl}$, $1.5 \mathrm{~mm} \mathrm{MgCl}, 10 \mathrm{~mm}$ Tris, $\mathrm{pH} 7.5,0.2 \%$ Triton $\mathrm{X}-100$, and $1 \mathrm{~mm}$ dithiothreitol. The homogenates were then centrifuged through a sucrose cushion ( $1 \mathrm{~m}$ sucrose, $50 \mathrm{~mm} \mathrm{NH}_{4} \mathrm{Cl}$, $0.1 \%$ Triton X-100, $5 \mathrm{mM} \mathrm{MgCl}_{2}$, and $10 \mathrm{~mm}$ Tris, pH 7.5). The resulting pellets were gently resuspended in $50 \%$ glycerol, $0.1 \mathrm{~mm}$ EDTA, $5 \mathrm{~mm} \mathrm{MgCl}_{2}$, and $50 \mathrm{~mm}$ HEPES, $\mathrm{pH}$ 7.5. In each reaction, equal amounts of nuclei were used, based on the quantity of DNA measured. The in vitro-labeled nascent transcripts were hybridized to plasmid cDNAs encoding rat TH (Leonard et al., 1987), DBH (McMahon et al., 1990), and cyclophilin (CPH; Danielson et al., 1988), as well as vector DNA (pBluescript) that were previously immobilized on nitrocellulose membranes. After proper washing, the filters were exposed to super-sensitive x-ray film (Eastman Kodak, Rochester, NY; Biomax MS). The autoradiograms were then digitally captured with a Datavision camera (model 261) and scanned by using ImagePro Plus software within the linear range of the signal. The signal intensity for each specific gene was

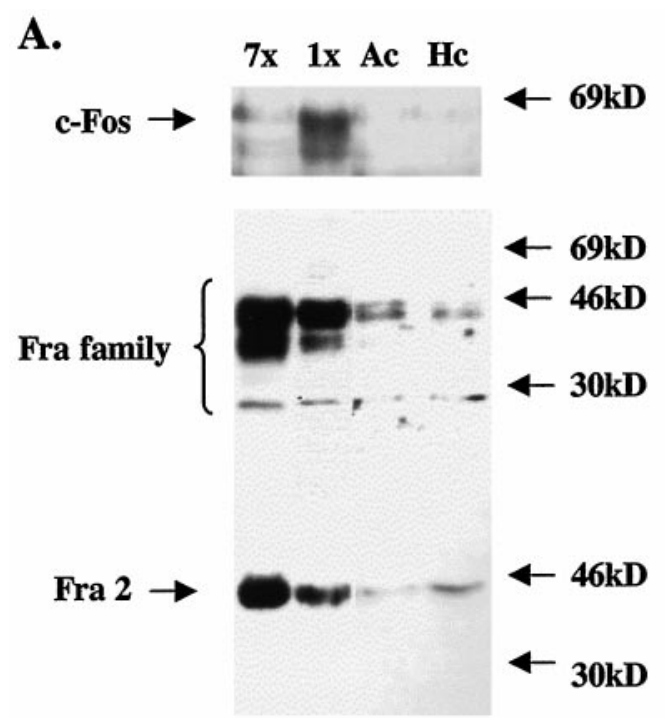

$\begin{array}{llll}1 & 2 & 3 & 4\end{array}$

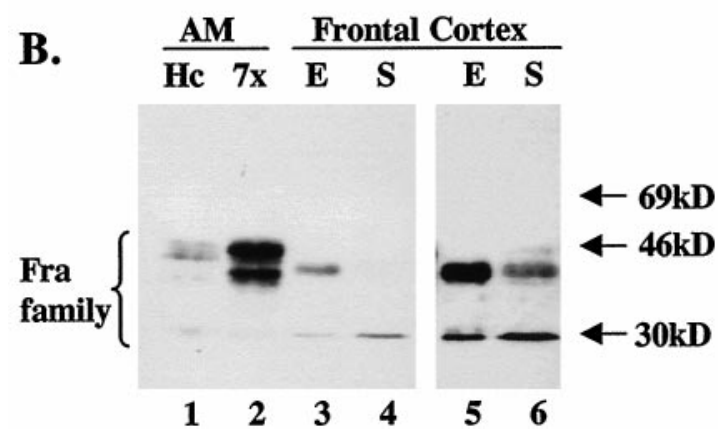

Figure 1. Differential effects of single and repeated immobilization on the expression of c-fos and Fos-related proteins. $A$, The levels of $\mathrm{c}-\mathrm{fos}$, the Fos-related-immunoreactive proteins (Fra family), and Fra2 were compared in total adrenomedullary homogenates from the corresponding control groups (Ac, absolute controls; Hc, handled controls) and from rats exposed to single $(1 \times)$ or repeated $(7 \times)$ immobilization stress by consecutive Western blot analyses, using antibodies specific for the indicated proteins. $B$, Comparison of the Fos-related-immunoreactive proteins induced in rat adrenal medulla $(A M)$ by repeated immobilization stress and in the frontal cortex by chronic ECS treatments. Identical amounts of whole-cell extracts from $\mathrm{AM}$ of handled controls $(\mathrm{Hc}$, lane 1$)$ and repeatedly immobilized ( $7 \times$, lane 2$)$ animals and from frontal cortex of animals, exposed to chronic electroconvulsive seizures (E, lanes 3 and 5) or shamtreated ( $S$, lanes 4 and 6 ) were subjected to Western blot analysis, using Fra family-specific antibody. The mobility of the marker proteins is indicated. Lanes 5 and 6 represent the same blot after longer exposure time.

calculated by subtracting background signals hybridized to the null vector, pBluescript.

Transfection. Transient transfection experiments were performed with CMV-Fra2 expression vector or control parental vector (provided by Dr. S. H. Yuspa, National Institute of Arthritis and Musculoskeletal and Skin Disease, Bethesda, MD) and promoter constructs driving the expression of a reporter gene. TH promoter construct contained $(-272 /+27)$ bp of the rat TH promoter fused to chloramphenicol acetyltransferase (CAT) reporter gene (a gift from Dr. D. Chikaraishi, Duke University Medical School, Durham, NC). DBH promoter construct had the first $248 \mathrm{bp}$ of the rat DBH promoter (McMahon and Sabban, 1992) subcloned into a pGL3Basic vector (Promega, Madison, WI) expressing firefly luciferase. PC12 cells were transfected using the Superfect Transfection Reagent (Qiagen, Hilden, Germany) according the manufacturer's protocol. Renilla luciferase reporter pRL-TK (Promega) was also added to control for transfection efficiency. After 12, 24, and $48 \mathrm{hr}$ the cells were harvested, and protein concentrations in total cell lysates were determined. Aliquots with equal amounts of protein were assayed for reporter gene activity. CAT activity was determined by a liquid scintillation method with $\left[{ }^{3} \mathrm{H}\right]$ chloramphenicol (Seed and Sheen, 1988). Comparisons between controls and Fra2expressing cells at the indicated times after transfection, in triplicate, were from the same experiment, with the same promoter construct plasmid 
DNA. Sequential quantitation of both firefly and Renilla luciferase activities was performed using the Dual-Luciferase Reporter Assay System from Promega.

Statistical analysis. Statistical analysis used ANOVA followed by Newman-Keuls post hoc comparisons.

\section{RESULTS}

\section{Induction of Fos-related antigens in rat adrenal medulla by immobilization stress}

To characterize the AP1 family members induced in response to single and repeated immobilization stress in adrenal medulla, we performed consecutive Western blot analyses (Fig. 1). Although barely detectable in controls as previously reported (Sabban et al., 1995; lanes 3 and 4), c-fos protein was markedly induced with $2 \mathrm{hr}$ single immobilization (lane 2). In contrast, after the last of seven consecutive episodes of stress, the levels of c-fos-immunoreactive protein were similar to controls. The same filters were probed using an antisera that recognizes all known Fos-like proteins (Young et al., 1991). Under basal conditions, low levels of Fras were observed. Immobilization stress resulted in robust induction of Fos-like proteins with $M_{\mathrm{r}}$ in the range of $30-46 \mathrm{kDa}$ in adrenal medulla (compare lanes 1 and 2 to lane 3). Similar patterns of Fra induction were observed in adrenal medulla after exposure to single (lane 2) and several times repeated (lane 1) immobilization. However, in contrast to c-fos, the levels after repeated stress were even higher than with a single exposure to immobilization.

Induction of Fos-related antigen-immunoreactive proteins in many different brain regions has been studied after different repeated or chronic treatments. FosB gene products were identified as transcription factors critical for long-term neural and behavioral plasticity to repeated stimuli (for review, see Nestler et al., 1999). To test if FosB or FosB-derived proteins are induced in adrenal medulla by immobilization stress, we used an $\mathrm{N}$ terminus-specific FosB antibody, which is able to recognize all FosB gene products. No significant changes were observed in the levels of immunoreactive Fos B $\left(M_{\mathrm{r}} 46 \mathrm{kDa}\right)$ or delta FosB proteins (with $M_{\mathrm{r}}$ values of $37,35,33,29$, and $28 \mathrm{kDa}$ ) with stress (data not shown). Furthermore, the Fos-like proteins induced in adrenal medulla by immobilization stress differed in $M_{\mathrm{r}}$ from the late Fras induced in frontal cortex after chronic electroconvulsive seizures (Fig. 1B).

The same filters were also probed with Fra2-specific antibody. Fra 2 was detected as one of the Fra family members markedly induced by stress. Increased Fra2 immunoreactivity was evident after a single stress (Fig. $1 A$, lane 2 ) and especially after repeated stress (Fig. 1A, lane 1).

\section{Increased transcription of stress-responsive gene with functional AP1 promoter element}

Next, we examined whether the induction of c-fos and Fos-related antigens by immobilization stress is associated with increased transcription of stress-responsive genes, which harbor functional AP1 motifs in their promoters. Figure $2 A$ shows a schematic diagram of the TH promoter and the sequence of the AP1 enhancer region. Nuclear run-on assays were used to evaluate changes in the relative rate of transcription of $\mathrm{TH}$ in response to single and repeated immobilization stress. Increased elongation of TH primary transcripts was found in nuclei from immobilized animals. Immobilization of the animals for $2 \mathrm{hr}$ once $(1 \times)$ or on each of 7 consecutive days $(7 \times)$ resulted in a threefold to fourfold increase in $\mathrm{TH}$ gene transcription (Fig. $2 B$ ), as compared to the corresponding group of unstressed animals (C) or animals handled daily ( $\mathrm{Hc})$. In contrast, the relative rate of transcription of a stress-unresponsive gene, $\mathrm{CPH}$, was unaffected by immobilization (Fig. 2B, insert).

\section{Variation and composition of AP1-binding activity after single and repeated stress}

To investigate which members of the Fos family of proteins may be involved in activation of $\mathrm{TH}$ gene transcription in adrenal medulla after exposure to stress, we performed gel shift assays. The oligonucleotide, spanning the AP1-like promoter element of the TH promoter (Fig. 2A), was labeled and incubated with nuclear ex-
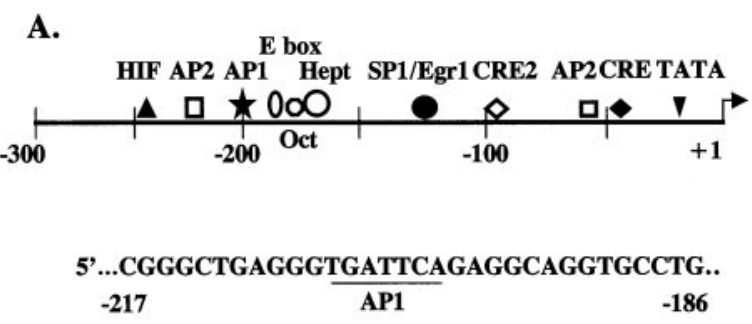

B.

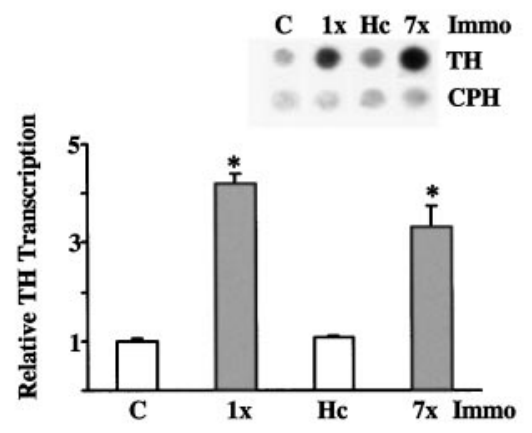

C.

D.
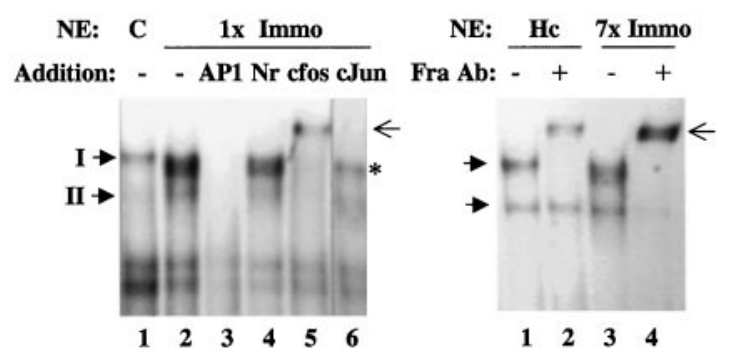

Figure 2. Stress increases tyrosine hydroxylase transcription and AP1binding activity. $A$, Diagram of the TH promoter and the sequence of the TH-AP1 probe used in electrophoretic mobility shift assays (based on Yoon and Chikaraishi, 1992). The confirmed enhancer elements are filled. $B$, The relative rate of $\mathrm{TH}$ transcription was evaluated by nuclear run on assay. The animals were untreated $(C)$ or exposed to immobilization stress for a single episode of $2 \mathrm{hr}(1 \times)$ or repeatedly on 7 consecutive days $(7 \times)$. The controls for the repeated stress were handled daily $(H c)$. The data (four independent experiments) are presented as mean \pm SE and normalized to the corresponding control. ${ }^{*} p<0.05$. The insert shows representative autoradiography for $\mathrm{TH}$ and $\mathrm{CPH}$ nascent gene transcripts. $C$, A single stress episode results in increased AP1-binding activity in adrenal medulla. The TH-AP1 oligonucleotide was incubated with nuclear extracts from control animals $(C$, lane 1$)$ or animals exposed to single immobilization $(1 \times$ Immo, lanes 2-6). Excess unlabeled oligonucleotide (AP1) or non-related oligonucleotide $(\mathrm{Nr})$ was added together with the labeled probe (lanes 3 and 4 ). For antibody supershift experiments, the extracts were pre-incubated with a $\alpha$-c-fos (lane 5) or $\alpha$-c-Jun (lane 6)-specific antibodies, as described in Materials and Methods. Complex I is induced by stress and consists of c-fos (supershift indicated by an arrow) and c-Jun (asterisk) proteins. D, AP1-like complexes enhanced by repeated stress contain Fos-related antigens. Nuclear extracts from handled controls ( $\mathrm{Hc}$; lanes 1 and 2$)$ or repeatedly immobilized rats $(7 \times$ Immo; lanes 3 and 4$)$ were incubated with the labeled TH-AP1 oligonucleotide in the presence $(+)$ or absence $(-)$ of an antibody that recognizes all members of the Fra family (supershifted complex is indicated by arrow).

tracts isolated from adrenal medulla of controls and animals exposed to stress. Two major DNA-protein complexes of low mobility were formed (Fig. 2C, lane 1). The formation of complex I (or complexes with similar mobility) was greatly induced by single immobilization stress, whereas complex II was barely changed (lane 2), as reported previously (Nankova et al., 1994). Both complexes were efficiently competed by addition of excess unlabeled AP1 oligonucleotide (lane 3), but not affected by addition of the same amount of nonrelated oligonucleotide (lane 4). The DNA-protein complex induced by single immobilization (complex I) contains 


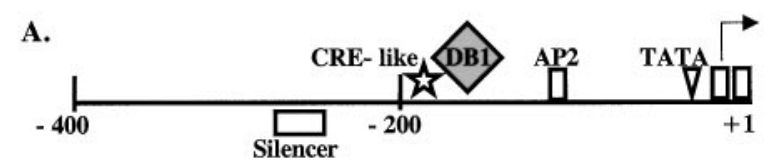

DB1

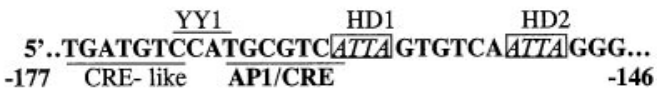

B.

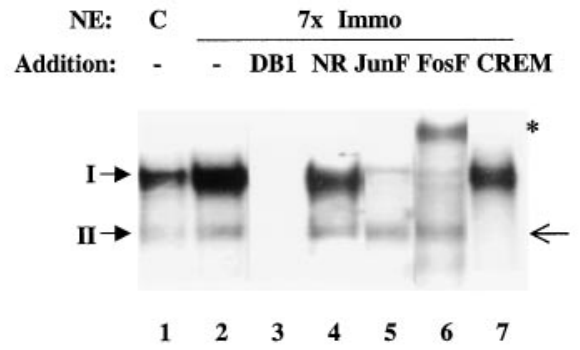

C.

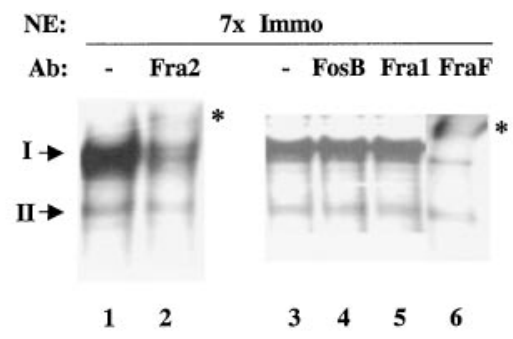

Figure 3. Stress induces increased binding of AP1-like factors to the DB1 multifunctional promoter element. $A$, Schematic diagram of the rat DBH promoter. The DB1 multifunctional enhancer, involved in regulation of basal and second messenger-inducible expression, is shown in detail (based on McMahon and Sabban, 1992; Shaskus et al., 1992). B, The binding of AP1-like factors is increased after repeated immobilization stress. Nuclear extracts from adrenal medulla of control rats $(C$, lane 1$)$ and animals exposed to seven daily repeated immobilizations ( $7 \times$ Immo, lanes 2-7) were incubated with labeled DB1 oligonucleotide. A 100-fold excess unlabeled oligonucleotide $(D B 1)$ or non-related oligonucleotide $(N R)$ were added together with the labeled probe (lanes 3 and 4 ). For antibody supershift experiments, the extracts were pre-incubated with antisera to Jun (lane 5), Fos (lane 6), or CREM (lane 7) family proteins, as described in Materials and Methods. The asterisk indicates the supershifted complex I, and the arrow indicates complex II affected by CREM antisera. $C$, Fra2 is the Fos family member involved in the interaction with DB1 promoter element. Antibody supershift experiments with nuclear extracts from adrenal medulla of repeatedly immobilized $(7 \times$ Immo) animals and antisera specific for the family of Fos-related proteins $(\mathrm{FraF})$ as well as for individual members: Fra1, Fra2, and FosB The position of the supershifted complex I is indicated by asterisks.

mainly c-fos and c-Jun as revealed by disruption or supershift of the band after addition of specific antibodies (lanes 5 and 6 ). Repeated immobilizations also resulted in increased formation of a complex of similar mobility (Fig. 2D, lane 3), although c-fos is no longer present (Fig. 1, lane 2). Addition of Fra family-specific antibody efficiently supershifted this complex in extracts from handled controls and repeatedly immobilized rats (lanes 2 and 4 ), which indicates that some Fos family members are involved. Complex II was not significantly influenced by these treatments.

Next, we examined the binding to the AP1-like motif of another stress-responsive gene, DBH. The upstream DBH promoter region is shown on Figure $3 A$ (McMahon and Sabban, 1992; Shaskus et al., 1992). An oligonucleotide spanning the multifunctional enhancer region DB1 in the promoter was radiolabeled and used in gel shifts. Incubation with nuclear extracts from adrenal medulla of control (Fig. 3B, lane 1) or immobilized (lane 2) animals resulted in formation of two major DNA-protein complexes. The specificity of complexes formed under these conditions was confirmed by competition with 100-fold excess of specific (DB1, lane 3) and lack of competition with nonrelated oligonucleotides $(\mathrm{Nr}$, lane 4$)$. In addition, replacement mutation of the AP1/CRE motif at position -168 to -162 rendered the DB1 oligonucleotide into a nonspecific competitor in the binding reaction (data not shown).

To identify the factors that bind to DB1 sequence, antibodies specific for Fos-, Jun-, and CREB families of proteins were included in the DNA-binding reaction. Fos and Jun family of proteins were identified as proteins that comprise the slower mobility complex I enhanced by immobilization stress, based on the ability of antibodies against these proteins to diminish the intensity of the binding complex or to form a supershifted band (lanes 5 and 6 ). In contrast, CREM-specific antiserum supershifted the complex with highest mobility (complex II, arrow), that is not affected by immobilization stress (Fig. 3B, lane 7). CREB and ATF1 were not identified in the DNA-protein complexes formed with the DB1 oligonucleotide (data not shown).

To further examine the transcription factors involved in DNAprotein interactions at the DB1 promoter element, we performed supershift analyses with antibodies specific for individual Fos family members (Fig. 3C). A c-fos specific antibody was unable to change the migration pattern (data not shown), suggesting that c-fos may not be involved in this interaction. This finding is not surprising, because c-fos is not induced by repeated stress (Fig. 1). Addition of Fra-family specific antibody efficiently supershifted complex I (lane 6), which indicates the presence of a Fos family member. Antibodies against Fra1 or FosB did not alter the gel shift pattern (lanes 4 and 5). In contrast, Fra2-specific antiserum supershifted complex I (lane 2). Taken together, our results suggest for the first time the importance of Fra2 in the transcriptional regulation of gene expression after repeated immobilization stress.

\section{TH and DBH: potential target genes for Fras induced in} adrenal medulla by immobilization

Given that repeated immobilization stress triggers persistent increases in the expression of TH and DBH genes (Kvetnansky and Sabban, 1998; Nankova and Sabban, 1999), we tested the possibility that long-lasting induction of Fras (Fra2) may correlate with the prolonged transcriptional activation of $\mathrm{TH}$ and $\mathrm{DBH}$ in response to chronic stress. Animals were exposed to repeated immobilizations on 7 consecutive days, and they were killed immediately or 1 or $2 \mathrm{~d}$ after the last episode of stress. Representative Western blots with Fra family or Fra2-specific antibodies are shown on Figure 4. Compared to the handled controls (Fig. 4A, lane 1), repeated exposure to stress resulted in increased expression of Fos-related antigens in adrenal medulla (lane 2). The levels of Fra proteins, although no longer maximal, remained higher than in controls when examined 1 or $2 \mathrm{~d}$ after the last stress session (Fig. $4 A$, lanes 3 and 4 ). Marked induction of Fra2 by $7 \times$ Immo was also observed (Fig. 4B, compare lanes 1 and 2). One or two days after cessation of the stress, levels of Fra2 declined but remained higher than controls (Fig. 4B, lanes 3 and 4; see the summary data on the right panel).

The relative rate of $\mathrm{TH}$ and $\mathrm{DBH}$ transcription was also examined under these conditions (Fig. 4C). Repeated stress was found to evoke threefold to fourfold increases in the transcription of both genes, evident even $1 \mathrm{~d}$ after the last episode of stress. In contrast, the expression of the stress unresponsive gene $\mathrm{CPH}$ was not affected (see the insert). Taken together the observed pattern of induction and DNA-binding activities of Fras by stress suggest that they may participate in the sustained transcriptional activation of $\mathrm{TH}$ and $\mathrm{DBH}$ genes after repeated immobilization.

\section{Fra2 increases transcription from TH and DBH promoters}

Having demonstrated that exposure to immobilization stress stimulates the expression of Fras, including Fra2 in rat adrenal medulla, associated with increased AP1-like binding and stimulated transcription of AP1-harboring genes $\mathrm{TH}$ and $\mathrm{DBH}$, our next aim was 
A. Fra family

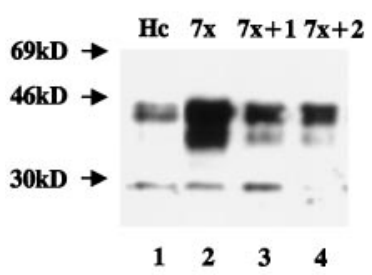

B. Fra2

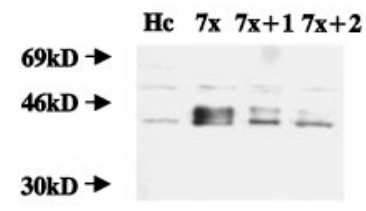

$\begin{array}{llll}1 & 2 & 3 & 4\end{array}$

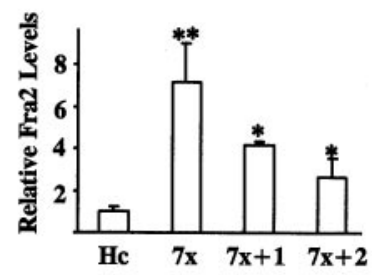

C.

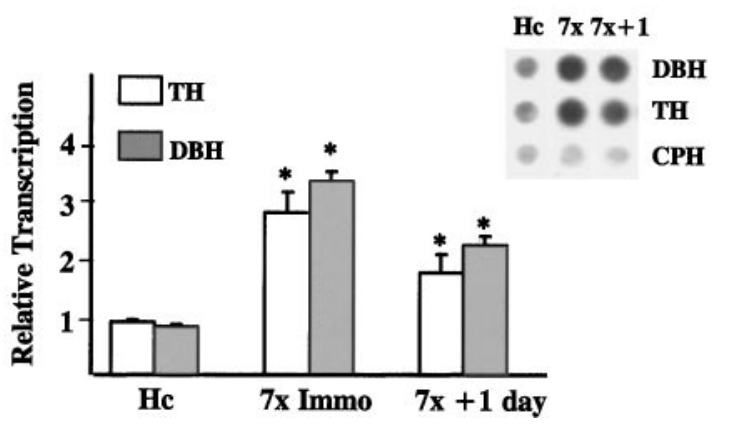

Figure 4. Repeated immobilization stress evokes long-lasting induction of Fra family/Fra2 and sustained rise in the transcription of AP1-regulated stress-responsive genes TH and DBH. Animals were subjected to repeated immobilizations and killed immediately after the last stress episode $(7 \times)$, $1 \mathrm{~d}$ later $(7 \mathrm{X}+1)$, or after $2 \mathrm{~d}(7 \mathrm{X}+2)$. Changes in the expression of Fra family of proteins (Fig. $4 A$ ) or of Fra2 (Fig. 4B) were examined in adrenal medulla by consecutive Western blot analysis and compared to the corresponding handled controls. The immunoblots probed with Fra2 antibody were quantified within the linear range of the signal. The data from two independent experiments, with four to eight individual animals per experimental group were normalized to the respective controls and presented as mean \pm SE on the right panel. ${ }^{*} p<0.05 ;{ }^{*} p<0.01$. The left adrenal medullae from the same animals were used for nuclear run on assays of transcription. The summary data from three independent experiments, presented as mean $\pm \mathrm{SE}$ and normalized to the corresponding control, are given in Figure $4 C,{ }^{*} p<0.05$. The insert shows a typical autoradiograph for $\mathrm{TH}, \mathrm{DBH}$, and the stress-unresponsive gene $\mathrm{CPH}$.

to evaluate whether Fra2 can directly affect their transcription. Therefore, we cotransfected PC12 cells with constructs in which a reporter activity is driven by a fragment of the rat $\mathrm{TH}$ or $\mathrm{DBH}$ promoter and with a Fra2 expression vector. Analysis of the reporter activities (Fig. 5) showed that over expression of Fra2 resulted in twofold to threefold, statistically significant upregulation of both $\mathrm{TH}$ and $\mathrm{DBH}$ promoter activity, when examined $24 \mathrm{hr}$ after transfection.

\section{DISCUSSION}

This study implicates Fra2 in underlying the persistent activation of $\mathrm{TH}$ and $\mathrm{DBH}$ transcription in adrenal medulla in response to repeated immobilization stress. Fra2 was identified originally in growth-stimulated chicken embryo fibroblasts (Nishina et al., 1990) as a novel protein cross-reactive with antiserum to c-fos. Cloning and characterization of the mouse fra-2 gene (Foletta et al., 1994)

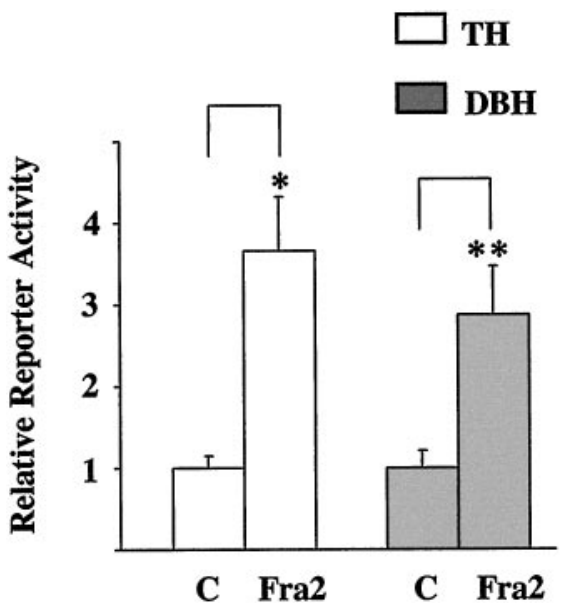

Figure 5. Effect of Fra2 on TH and DBH promoter activity. Two combinations of plasmids were cotransfected into PC12 cells: control mix $(C)$, containing $\mathrm{TH}-\mathrm{CAT}$ promoter construct or $\mathrm{DBH}$-firefly luciferase promoter construct and CMV- $\beta$ Gal plasmid; and Fra2 mix (Fra2), consisting of CMV-Fra2- expression vector and the respective promoter construct. The transfected cells (in triplicates) were incubated for $24 \mathrm{hr}$. Relative reporter gene activity was determined in aliquots of cell lysates with equal amount of total protein and normalized to their matched controls. The summary data (mean \pm SE) for both promoter constructs are shown. $* p<0.05$.

revealed similar overall gene structure (four exons and three introns) between $c$-fos and fra-2. High Fra 2 mRNA expression has been observed in a diverse range of adult mouse tissues (ovary, stomach, lung, intestine, brain, and heart; Foletta et al., 1994). Here we found detectable levels of Fra2 protein in total homogenates from adrenal medulla of control rats. Exposure to immobilization stress elicits robust induction of several members of the fos family of proteins, including Fra2. Various agents have been reported to cause induction of Fra2 mRNA and protein expression: serum stimulation, the phorbol ester TPA, cAMP, and calcium ionophores in different cell systems; and in vivo metrazole-induced seizures increase Fra2 expression in the rat hippocampus (for review, see Foletta, 1996).

Our work is the first to show activation of Fra2 expression by in vivo stress. Similar to other stimuli (for review, see Foletta, 1996), the pattern of induction of c-fos and Fra2 differed. Whereas c-fos immunoreactivity was rapidly but transiently induced by a single episode of stress, Fra2 expression was stimulated by both single and repeated immobilization. Multiple bands in the range of 30-50 $\mathrm{kDa}$ were visualized with Fra family-specific antibody, suggesting that other Fos-related antigens were also induced by stress. When directly compared, the pattern of Fos-related proteins induced in the adrenal medulla by repeated immobilization stress and in the frontal cortex by chronic electroconvulsive seizures differed. In contrast to the effect of chronic challenges in the brain (Hope et al., 1994a; Chen et al., 1997; Hiroi et al., 1998; Nestler et al., 1999), immobilization stress did not stimulate the expression of FosB and/or the truncated splice variants of gene-Delta FosB isoforms in adrenal medulla. These results are consistent with the hypothesis that different members of the extended Fos-family of proteins seem to be involved in central and peripheral responses to chronic stimuli.

It has been shown that stress-elicited increases in the expression of genes that encode catecholamine biosynthetic enzymes may involve transcriptional activation (Nankova et al., 1994, 1999; Osterhout et al., 1997). Depending on the duration and reiteration of the stress signal, different phases of transcriptional activation were observed (Nankova and Sabban, 1999; Nankova et al., 1999). Both $\mathrm{TH}$ and DBH genes contain functional AP1-like sites in their promoters (Kumer and Vrana, 1996; Sabban, 1997; Swanson et al., 1998). Here we demonstrated that the induction of Fos family of proteins by stress and the resulting increases in AP1-binding activ- 
ity parallel the transcriptional upregulation of $\mathrm{TH}$ and $\mathrm{DBH}$. It has been shown that Fra2 displays similar dimerization and DNAbinding properties to that of c-fos protein, because it forms stable heterodimers with Jun proteins and binds specifically to AP1 sites or related sequences (Suzuki et al., 1991). Although both c-fos and Fra2 are stimulated by single immobilization in adrenal medulla, the complexes formed at the TH AP1-like site and elevated by single stress consisted mainly of c-fos/c-Jun dimers. In contrast, c-fos is unlikely to be involved in the transcriptional activation of DBH by single immobilization, as revealed by the results from gel shifts presented here and earlier photochemical cross-linking experiments (Nankova et al., 1994; Sabban et al., 1995). Thus, with a single stress signal different sets of transcription factors within the same adrenomedullary extracts interact with TH and DBH AP1like promoter elements and may mediate the differential regulation of TH and DBH gene expression (Nankova et al., 1999). In this regard, it has been shown that various Fos/Jun heterodimers have different affinities for AP1-like sites, partly attributed to the different DNA sequences surrounding the core AP1 sequence (Ryseck and Bravo, 1991).

Repeated stress triggers sustained elevations in the relative rates of TH and DBH gene transcription, which is reflected in accumulation of the corresponding mRNAs (Sabban et al., 1995; Nankova and Sabban, 1999). These events are probably mediated by longlasting changes in the levels and/or activity of the involved transcription factors. After repeated episodes of stress, c-fos is no longer elevated. In contrast, Fra2 expression is robustly induced, and increased Fra2 immunoreactivity is observed at least $2 \mathrm{~d}$ after the last stress episode. The DNA-protein complexes, formed at $\mathrm{TH}$ and DBH AP1-like enhancers and elevated by repeated immobilization stress, consist mainly of Fra2 (and a Jun family member, most probably c-Jun and/or Jun D). Thus, distinct AP1 heterodimers are formed during the transcriptional activation of the genes for catecholamine biosynthetic enzymes by stress, and different members of the extended Fos-family of proteins may be involved in mediating the acute and chronic effects of stress.

Variations in Jun and Fos protein expression and AP1-binding activity have been reported in cycling, resting, and stimulated fibroblasts (Lallemand et al., 1997). The authors suggested that AP1 activity is finely regulated and in a complex manner during the G0-G1 transition, and involves changes in protein expression and in posttranslational modification. In vitro transfection experiments with chicken Fra2 promoter constructs revealed high levels of transcription after serum stimulation, mediated by AP1, CRE-like, and SRE promoter elements. This induction was delayed and prolonged compared to that of c-fos (Sonobe et al., 1995). The "efficacy" of the DNA-binding transcription factors can be also modulated by phosphorylation (Karin, 1995; Fry and Farnham, 1999). All AP1 proteins are phosphoproteins, and hyperphosphorylation or dephosphorylation may affect their DNA-binding and transactivation activities (for review, see Foletta, 1996). Phosphorylation of Fra2 by ERK2 converts it from an inefficient transcriptional activator to an active one. Furthermore, Fra2 expression is autoregulated in response to the phosphorylation status of its gene product (Murakami et al., 1997). In vitro studies demonstrated that Fra2 could be phosphorylated by several kinases, including PKA, PKC, MAP kinase and cyclin-dependent kinase 1-cdc2 (Gruda et al., 1994). Interestingly Fra2-immunoreactive band is evident as a doublet significantly induced by single and especially by repeated immobilization. Which specific pathways are activated in response to acute and chronic stress and how they would affect Fra2 regulation in adrenal medulla remains to be determined.

The results presented here indicate likely involvement of Fra2 in the activation of $\mathrm{TH}$ and $\mathrm{DBH}$ expression in vivo in rat adrenal medulla triggered by repeated immobilization stress. The putative importance of the transcription factor Fra2 in the regulation of TH and $\mathrm{DBH}$ promoter activity was tested in PC12 cells, the most physiologically relevant cell line to the adrenal medulla (Fry and Farnham, 1999). We chose to use the natural proximal rat TH and $\mathrm{DBH}$ promoters for transient transfection studies instead of syn- thetic constructs with multiple tandem consensus AP1 sites driving the expression of a reporter gene. It has been shown that the presence of overlapping or closely spaced transcription factorbinding sites often results in context-dependent transcriptional regulation of a given promoter (for review, see Fry and Farnham, 1999). The composite region of the proximal rat DBH promoter (DB1) contains potential adjacent and overlapping cis-regulatory elements, essential for both basal and second messenger inducible transcription of the gene (McMahon and Sabban, 1992; Shaskus et al., 1992; Afar et al., 1996; Seo et al., 1996). Thus, the ability of a different AP1- or AP1-like transcription factors to regulate $\mathrm{DBH}$ transcription may be influenced in vivo by the promoter context. Even without cotransfection of a Jun-expression vector, exogeneous Fra2 expression triggered modest, but statistically significant, upregulation of both $\mathrm{TH}$ and $\mathrm{DBH}$ promoters.

The results of this study revealed differential induction of c-fos and Fos-related antigens in rat adrenal medulla in vivo induced by single and repeated immobilization stress. The robust stimulation of Fra2 expression paralleled the increased transcription of the stress-responsive genes TH and DBH. Fra2 may play an important role in mediating the stress response in the adrenal medulla and may contribute to the adaptation of the norepinephrine-producing system to in vivo challenges.

\section{REFERENCES}

Afar R, Silverman R, Aguanno A, Albert VR (1996) Positive and negative elements contribute to the cell-specific expression of the rat dopamine $\beta$-hydroxylase gene. Mol Brain Res 36:79-92.

Atkins JB, Chlan-Fourney J, Nye HE, Hiroi N, Carlezon Jr WA, Nestler EJ (1999) Region-specific induction of deltaFosB by repeated administration of typical versus atypical antipsychotic drugs. Synapse 33:118-128.

Bing G, McMillian M, Kim H, Pennypacker K, Feng Z, Qi Q, Kong LY, Iadarola M, Hong JS (1996) Long-term expression of the 35,000 mol. wt fos-related antigen in rat brain after kainic acid treatment. Neuroscience 73:1159-1174.

Campeau S, Hayward MD, Hope BT, Rosen JB, Nestler EJ, Davis M (1991) Induction of the c-fos proto-oncogene in rat amygdala during unconditioned and conditioned fear. Brain Res 565:349-352.

Chaudhuri A (1997) Neural activity mapping with inducible transcription factors. NeuroReport 8:3-7.

Chen J, Kelz MB, Hope BT, Nakabeppu Y, Nestler EJ (1997) Chronic Fos-related antigens: stable variants of deltaFosB induced in brain by chronic treatments. J Neurosci 17:4933-4941.

Danielson PE, Forss-Petter S, Brow MA, Calavetta L, Douglass J, Milner RJ, Sutcliffe JG (1988) p1B15: a cDNA clone of the rat mRNA encoding cyclophilin. DNA 7:261-267.

Del BEA, Silveira MC, Graeff FG, Garcia-Cairasco N, Guimaraes FS (1998) Differential expression of c-fos mRNA and Fos protein in the rat brain after restraint stress or pentylenetetrazol-induced seizures. Cell Mol Neurobiol 18:339-346.

Dignam JD, Lebovitz RM, Roeder RG (1983) Accurate transcription initiation by RNA polymerase II in a soluble extract from isolated mammalian nuclei. Nucleic Acids Res 11:1475-1489.

Doucet JP, Nakabeppu Y, Bedard PJ, Hope BT, Nestler EJ, Jasmin BJ, Chen JS, Iadarola MJ, St-Jean M, Wigle N, Blanchet P, Grondin R, Robertson GS (1996) Chronic alterations in dopaminergic neurotransmission produce a persistent elevation of deltaFosB-like protein(s) in both the rodent and primate striatum. Eur J Neurosci 8:365-381.

Foletta VC (1996) Transcription factor AP-1, and the role of Fra-2. Immunol Cell Biol 74:121-133.

Foletta VC, Sonobe MH, Suzuki T, Endo T, Iba H, Cohen DR (1994) Cloning and characterisation of the mouse fra-2 gene. Oncogene 9:3305-3311.

Fossom LH, Sterling CR, Tank AW (1992) Regulation of tyrosine hydroxylase gene transcription rate and tyrosine hydroxylase mRNA stability by cyclic AMP and glucocorticoid. Mol Pharmacol 42:898-908.

Fry CJ, Farnham PJ (1999) Context-dependent transcriptional regulation. J Biol Chem 274:29583-29586.

Gruda MC, Kovary K, Metz R, Bravo R (1994) Regulation of Fra-1 and Fra-2 phosphorylation differs during the cell cycle of fibroblasts and phosphorylation in vitro by MAP kinase affects DNA binding activity. Oncogene 9:2537-2547.

Hiroi N, Marek GJ, Brown JR, Ye H, Saudou F, Vaidya VA, Duman RS, Greenberg ME, Nestler EJ (1998) Essential role of the fosB gene in molecular, cellular, and behavioral actions of chronic electroconvulsive seizures. J Neurosci 18:6952-6962.

Hope BT, Kelz MB, Duman RS, Nestler EJ (1994a) Chronic electroconvulsive seizure (ECS) treatment results in expression of a long-lasting AP-1 complex in brain with altered composition and characteristics. J Neurosci 14:4318-4328.

Hope BT, Nye HE, Kelz MB, Self DW, Iadarola MJ, Nakabeppu Y, 
Duman RS, Nestler EJ (1994b) Induction of a long-lasting AP-1 complex composed of altered Fos-like proteins in the brain caused by cocaine and other chronic treatments. Neuron 13:1235-1244.

Karin M (1995) The regulation of AP-1 activity by mitogen-activated protein kinases. J Biol Chem 270:16483-16486.

Kovacs KJ (1998) c-Fos as a transcription factor: a stressful (re)view from a functional map. Neurochem Int 33:287-297.

Kumer SC, Vrana KE (1996) Intricate regulation of tyrosine hydroxylase activity and gene expression. J Neurochem 67:443-462.

Kvetnansky R, Sabban EL (1998) Stress and molecular biology of neurotransmitter-related enzymes. Ann NY Acad Sci 851:42-356.

Lallemand D, Spyrou G, Yaniv M, Pfarr CM (1997) Variations in Jun and Fos protein expression and AP-1 activity in cycling, resting and stimulated fibroblasts. Oncogene 14:819-830.

Leonard DGB, Ziff EB, Green LA (1987) Identification and characterization of mRNAs regulated by nerve growth factor in PC12 cells. Mol Cell Biol 7:3156-3167.

McKnight GS, Palmiter RD (1979) Transcriptional regulation of the ovalbumin and conalbumin genes by steroid hormones in chick oviduct. J Biol Chem 254:9050-9058.

McMahon A, Sabban E (1992) Regulation of Expression of Dopamine $\beta$-hydroxylase in PC12 cells by glucocorticoids and cyclic AMP analogs. J Neurochem 59:2040-2047.

McMahon A, Geertman R, Sabban EL (1990) Rat dopamine $\beta$-hydroxylase: molecular cloning and characterization of the cDNA and regulation of the mRNA by reserpine. J Neurosci Res 25:395-404.

McMahon A, Kvetnansky R, Fukuhara K, Weise VK, Kopin I, Sabban EL (1992) Regulation of tyrosine hydroxylase and dopamine $\beta$-hydroxylase mRNA levels in rat adrenals by a single and repeated immobilization stress. J Neurochem 58:2124-2130.

Moratalla R, Elibol B, Vallejo M, Graybiel AM (1996) Network-level changes in expression of inducible Fos-Jun proteins in the striatum during chronic cocaine treatment and withdrawal. Neuron 17:147-156.

Morgan JI, Curran T (1995) Immediate-early genes: ten years on. Trends Neurosci 18:66-67.

Murakami M, Sonobe MH, Ui M, Kabuyama Y, Watanabe H, Wada T, Handa H, Iba H (1997) Phosphorylation and high level expression of Fra-2 in v-src transformed cells: a pathway of activation of endogenous AP-1. Oncogene 14:2435-2444.

Nankova BB, Sabban EL (1999) Multiple signalling pathways exist in the stress-triggered regulation of gene expression for catecholamine biosynthetic enzymes and several neuropeptides in the rat adrenal medulla. Acta Physiol Scand 167:1-9.

Nankova B, Devlin D, Kvetnansky R, Kopin IJ, Sabban EL (1993) Repeated immobilization stress increases the binding of c-fos-like proteins to a rat dopamine $\beta$-hydroxylase promoter enhancer sequence. J Neurochem 61:776-779.

Nankova B, Kvetnansky R, McMahon A, Viskupic E, Hiremagalur B, Frankle G, Fukuhara K, Kopin IJ, Sabban EL (1994) Induction of tyrosine hydroxylase gene expression by a nonneuronal nonpituitarymediated mechanism in immobilization stress. Proc Natl Acad Sci USA 91:5937-5941.

Nankova B, Kvetnansky R, Hiremagalur B, Sabban B, Rusnak M, Sabban EL (1996) Immobilization stress elevates gene expression for catecholamine biosynthetic enzymes and some neuropeptides in rat sympathetic ganglia: effects of $\mathrm{ACTH}$ and glucocorticoids. Mol Endocrinol 137:5597-5604.

Nankova BB, Tank AW, Sabban EL (1999) Transient or sustained transcriptional activation of the genes encoding rat adrenomedullary catecholamine biosynthetic enzymes by different durations of immobilization stress. Neuroscience 94:803-808.

Nestler EJ, Kelz MB, Chen J (1999) DeltaFosB: a molecular mediator of long-term neural and behavioral plasticity. Brain Res 835:10-17.

Nishina H, Sato H, Suzuki T, Sato M, Iba H (1990) Isolation and characterization of fra-2, an additional member of the fos gene family. Proc Nat Acad Sci USA 87:3619-3623.
Nye HE, Nestler EJ (1996) Induction of chronic Fos-related antigens in rat brain by chronic morphine administration. Mol Pharmacol 49:636-645.

Nye HE, Hope BT, Kelz MB, Iadarola M, Nestler EJ (1995) Pharmacological studies of the regulation of chronic FOS-related antigen induction by cocaine in the striatum and nucleus accumbens. J Pharmacol Exp Ther 275:1671-1680.

Osterhout CA, Chikaraishi DM, Tank AW (1997) Induction of tyrosine hydroxylase protein and a transgene containing tyrosine hydroxylase $5^{\prime}$ flanking sequences by stress in mouse adrenal gland. J Neurochem 68:1071-1077.

Palkovits M, Baffi JS, Dvori S (1995) Neural organization of stress response: pain-induced c-fos expression in brain stem catecholaminergic cell groups. Ann NY Acad Sci 771:313-326.

Pennypacker KR, Hong JS (1995) Kainate-induced changes in gene expression in the rat hippocampus. Prog Brain Res 105:105-116.

Pich EM, Pagliusi SR, Tessari M, Talabot-Ayer D, Hooft van HR, Chiamulera C (1997) Common neural substrates for the addictive properties of nicotine and cocaine. Science 275:83-86.

Ryseck RP, Bravo R (1991) c-JUN, JUN B, and JUN D differ in their binding affinities to AP-1 and CRE consensus sequences: effect of FOS proteins. Oncogene 6:533-542.

Sabban EL, Hiremagalur B, Nankova B, Kvetnansky R (1995) Molecular biology of stress-elicited induction of catecholamine biosynthetic enzymes. Ann NY Acad Sci 771:327-338.

Sabban LE (1997) Control of Tyrosine Hydroxylase Gene Expression in Chromaffin and PC12 Cells. Semin Cell Dev Biol 8:101-111.

Senba E, Ueyama T (1997) Stress-induced expression of immediate early genes in the brain and peripheral organs of the rat. Neurosci Res 29:183-207.

Seed B, Sheen YP (1988) A simple phase-extraction assay for chloramphenicol acetyltransferase activity. Gene 67:271-277.

Seo H, Yank C, Kim HS, Kim KS (1996) Multiple protein factors interact with the cis-regulatory elements of the proximal promoter in a cellspecific manner and regulate transcription of the dopamine $\beta$-hydroxylase gene. J Neurosci 16:4102-4112.

Serova LI, Saez E, Spiegelman BM, Sabban EL (1998) c-Fos deficiency inhibits induction of mRNA for some, but not all, neurotransmitter biosynthetic enzymes by immobilization stress. J Neurochem 70:1935-1940.

Sharp FR, Sagar SM, Hicks K, Lowenstein D, Hisanaga K (1991) c-fos mRNA, Fos, and Fos-related antigen induction by hypertonic saline and stress. J Neurosci 11:2321-2331.

Shaskus J, Greco D, Asnani LP, Lewis EJ (1992) A bifunctional genetic regulatory element of the rat dopamine $\beta$-hydroxylase gene influences cell type specificity and second messenger-mediated transcription. J Biol Chem 267:18821-18830.

Sonobe MH, Yoshida T, Murakami M, Kameda T, Iba H (1995) fra-2 promoter can respond to serum-stimulation through AP-1 complexes. Oncogene 10:689-696.

Suzuki T, Okuno H, Yoshida T, Endo T, Nishina H, Iba H (1991) Difference in transcriptional regulatory function between c-Fos and Fra-2. Nucleic Acids Res 19:5537-5542.

Swanson DJ, Zellmer E, Lewis EJ (1998) AP1 proteins mediate the cAMP response of the dopamine beta-hydroxylase gene. J Biol Chem 273:24065-24074.

Umemoto S, Kawai Y, Ueyama T, Senba E (1997) Chronic glucocorticoid administration as well as repeated stress affects the subsequent acute immobilization stress-induced expression of immediate early genes but not that of NGFI-A. Neuroscience 80:763-773.

Yoon SO, Chikaraishi DM (1992) Tissue-specific transcription of the rat tyrosine hydroxylase gene requires synergy between an AP-1 motif and an overlapping E box-containing dyad. Neuron 9:55-67.

Young ST, Porrino LJ, Iadarola MJ (1991) Cocaine induces striatal c-fosimmunoreactive proteins via dopaminergic D1 receptors. Proc Natl Acad Sci USA 88:1291-1295. 